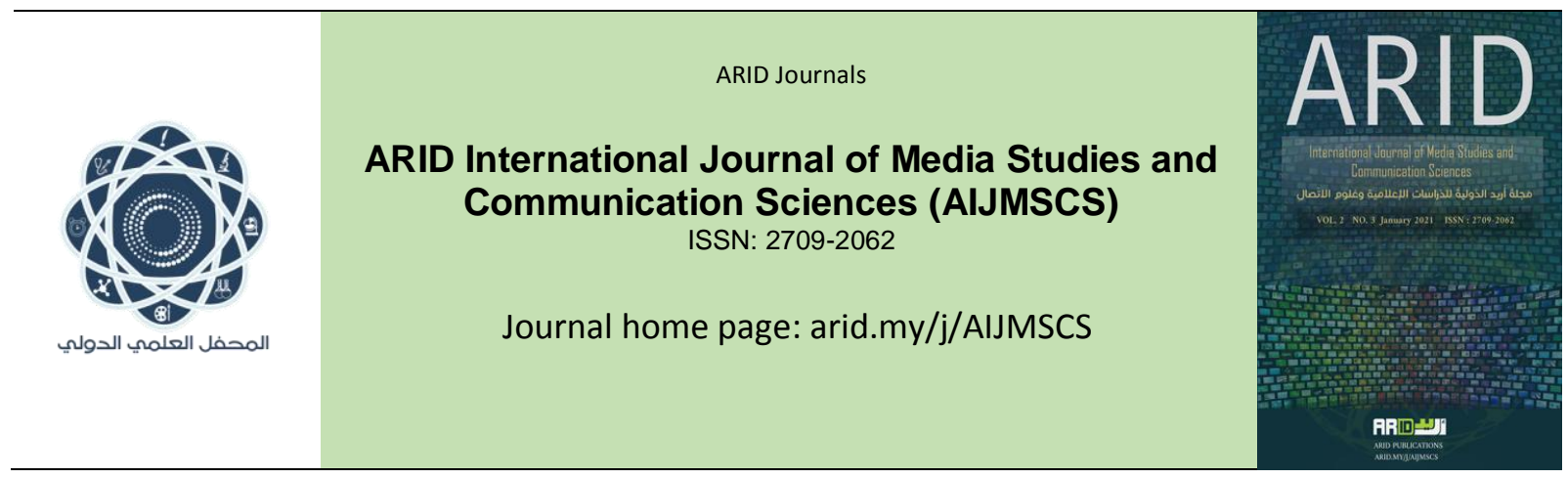

$$
\begin{aligned}
& \text { مَجلةُ أُويل اللَّوليةٌ للدراسات الإععلامية وعلوم الإتصال } \\
& \text { العدد } 3 \text { ، البحلد } 2 \text { ، كانون الثاني 2021م }
\end{aligned}
$$

\title{
Contents of Fake News on Social Media: Confrontation Means and Methods of Verification; A Field/Analytic Study
}

\author{
Wefaq hafud burkah \\ The department of journalism-College of media-Al-iraqia University-Baghdad-Iraq

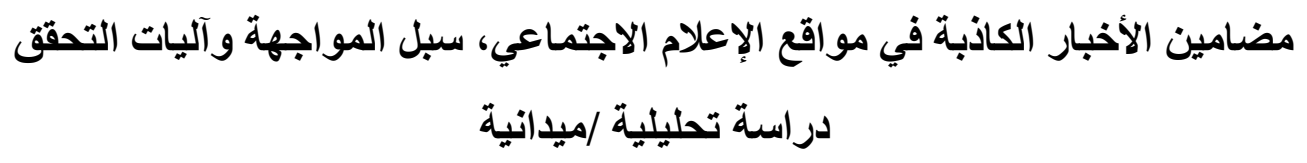

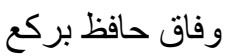$$
\text { قسم الصحافة_كلية الإعلام_الجامعة العر اقية -بغداد_العر اق }
$$ 


\begin{tabular}{l}
\hline A R T I C L E I N F O \\
\hline Article history: \\
Received 15/07/2020 \\
Received in revised form 12/09/2020 \\
Accepted 08/11/2020 \\
Available online 15/01/2021 \\
https://doi.org/10.36772/arid.aijmscs.2021.234 \\
\hline
\end{tabular}

\begin{abstract}
The paper studies the contents of the fake news shared by the social media users. Fake pieces of news are not the creation of this time. They have existed since the appearance of the communication media like journalism, television and radio. Those traditional media, however, sought not to circulate any false news that might affect their credibility, and hence their relationship to the masses. After the technological development that took place in the fields of information and communication, and then the emergence of the Internet, false pieces of news have started to spread more rapidly and widely than before due to the modern technological development in communicating and sharing information. The receiver has started to play the role of the journalist in communicating the events and what takes place around him. He has started to share and circulate the news on the social media for personal objectives or due to being backed by a specific body to affect the public opinion.

The paper is a descriptive study. A survey is used in the field and analytical studies. In the two studies, the researcher tries to identify the most important contents formed in the fake news that are shared on the social media and identify the characteristics of these pieces of news for the users. The researcher also attempts to find the means to face the fake news and how to verify its credibility. She has arrived at several conclusions, the most important of which is that most of the contents shared by the users of the social media, which have been revealed in both the analysed sites, are political, security, and then varied contents, such as natural disasters, modern technologies, historical events, entertainment and satire..As for the sites that contribute in sharing and circulating the news, Facebook, in spite of being the most important source of news for the sample, was the most prominent social medium where fake pieces of news were shared and circulated. The personal and public pages were prominent in circulating these pieces of fake news.
\end{abstract}

Keywords: Fake news- social media sites- verification methods 


\section{الملخص}

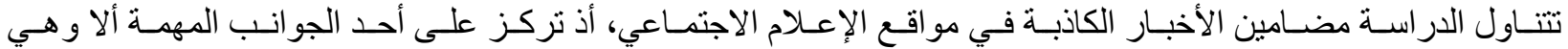

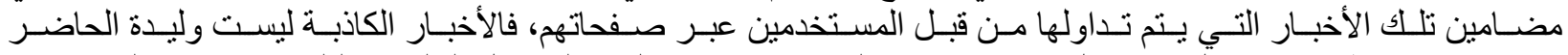

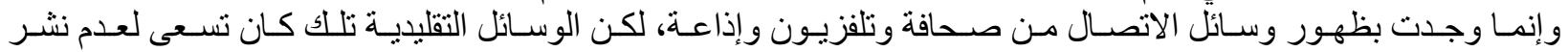

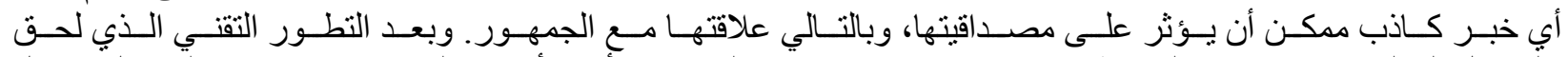

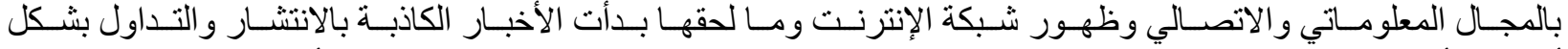

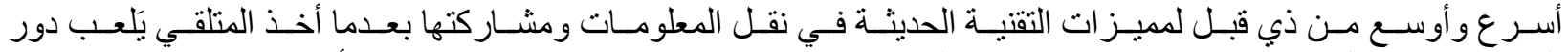

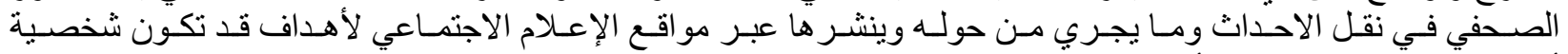
أو مدعومة من جهة معينة للتأثثر في الر أبي العام.

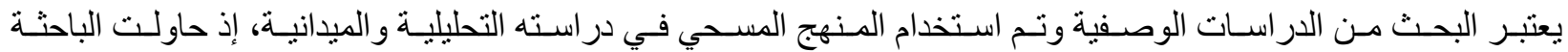

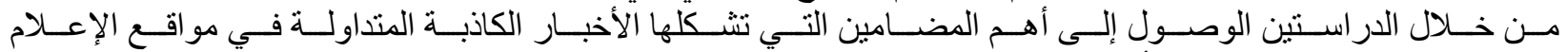

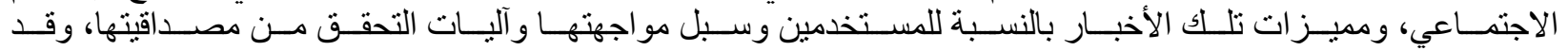

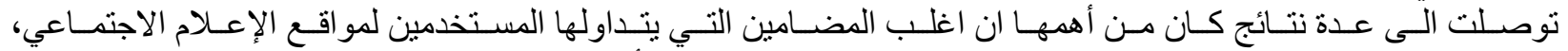

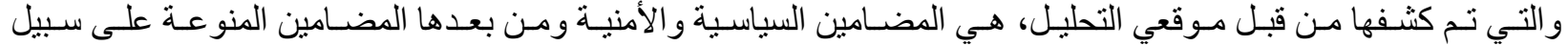

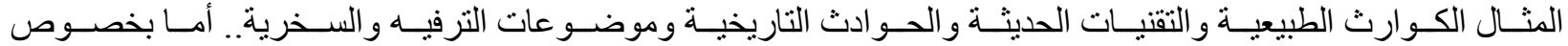

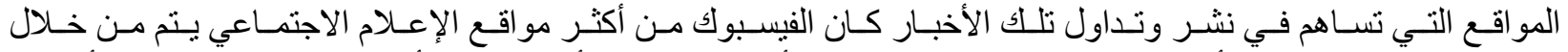

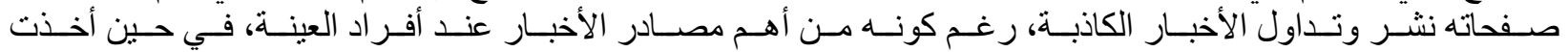

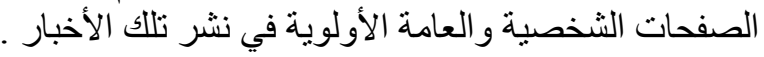

الكلمات المفتاحية: الأخبار الكاذبةــ مو اقع الإعلام الاجتماعيـ آليات التحقق 
تعالج الدراسة موضوعاً مهماً بدأ يظهر على الساحة الإعلامية من جديد بعدما قلت صناعته وبدأت تتلاشى ألا وهو الأخبار الكاذبة، لا يخفى بأن الأخبار الكاذبة موجودة بوجود الوسائل الإعلامية منذ بداياتها، وسعت المؤسسات الإعلامية لعدم نثر أو إذاعة أي خبر قد يظن المتلقي بأنه يتضمن جانب من الصحة أو يحتوي معلومات غير دقيقة تجنباً لوقو عها في المحظور وبذلك تفقد جمهور عريض من متابعيها.

ونتيجة للتطورات التقنية على الصعيد المعلوماتي و الاتصالي، ظهرت وسائل اتصالية جديدة مكنت المواطن من استخدامها بكل سهولة دون عناء أو عبء مادي أو رقيب، وفتحت الأبواب مشرعة لل لتجربة عَل الصحفي والخوض في غمار تلك التجربة، إذ سعى الفرد إلى إبداء رأيه و التعبير عنه بكل حرية وليس هذا فحسب و إنما نقل ما يدور حوله من أحداث وقضايا ونشر ها عبر المواقع الإلكترونية ومن ضمنها مو اقع الإعلام الاجتماعي...عندها أخذت الأخبار تتناقل وتتنشر بشكل أوسع واسرع من ذي قبل خصوصا على صفحات التواصل الاجتماعي ومن تلك الأخبار، الأخبار الكاذبة (المزيفة ـ الأضللة) ولا يقتصر تناقل ونثر تلك الأخبار على الأفر اد حسب، وانما هنالك حسابات آلية وجيوش الكترونية تقف وراؤها حكومات ومنظمات ومؤسسات تسعى للتأثير في الرأي وخلق حالة من البلبلة والانقسام أو الكر اهية بما يتو افق و الهدف الذي تسعى إليه. مشكلة البحث:

تدور مشكلة البحث حول ماهية مضامين الأخبار الكاذبة والتي يتم تداولها بين جمهور مستخدمي مو اقع الإعلام الاجتماعي على صفحاتهم الثخصية والعامة وحنى الإعلامية. ومن ذلك التساؤل تنتر ع عدة تساؤلات وهي: 1 - ماهي الموضو عات و القضايا التي تتناولها الأخبار الكاذبة على مو اقع الإعلام الاجتماعي؟

$$
2 \text { - ماهي تصنيفات الأخبار الكاذبة ومجالها الجغر افي؟ }
$$

3 - بماذا تتصف الأخبار الكاذبة في مواقع الإعلام الاجتماعي، وأهم المواقع التي تساهم بنشر ها وتداولها؟

4 - كيف يمكن للمنلقي أو القائم بالاتصال مو اجهة مثل تلك الأخبار؟ 5 - ماهي آليات التحقق من الأخبار الكاذبة من قبل المتلقي و القائم بالاتصال؟

أهمية البحث: ثأتي أهمية تناول مثل هذه الدراسة كون الأخبار الكاذبة والزائفة أخذت بالانتشار بشكل كبير في المواقع الإلكترونية وخاصة مو اقع الإعلام الاجتماعي كصفحات الفيس بوك وتويتر ويوتيوب و التيلغر ام وغير ها من المنصات. انتشار هذه الأخبار له خطورته على المجتمعات من حيث تأثيره على تشكيل الرأي العام بشكل عام وتأثيره على الفرد بشكل خاص 
وليس هذا فحسب وانما تأثيره على امن الدول والحكومات. فالمواطن في هذا العصر أصبح متلقي إيجابي قادر على التفاعل و المشاركة ويتوجب عليه في ظل الكثافة المعلوماتية أن يتعلم كيف يواجه تللك الأخبار وكيف يتحقق منها... ومن الناجية الاكاديمية تعالج الدراسة موضوعاً أخذ بالظهور مرة أخرى بطرق و أساليب إعلامية جديدة ومتنوعة، فنحن أمام إشكالية في مو اجهة مثل تلك الأخبار الكاذبة لسرعة انتشار ها اولاً وكثافة وجودها في مواقع الإعلام الاجتماعي ثانياً.. فسرعة تناقل هذه الأخبار بين الجمهور، لا يترك لهم الوقت الكافي للتحقق منها كــ(تحليلها أو تقييمها أو التأكد من مصادر ها...الخ) مما يساهم في انتشار ها بشكل كبير.

\section{اهداف البحث: يسعى البحث للتوصل إلىى ما يلي}

- التعرف إلى أكثر القضايا التي تناولتها مضامين الأخبار الكاذبة. - معرفة أهم تصنيفات الأخبار المنشورة في المو اقع ومجالها الجغر افي. - تحديد صفات الأخبار الكاذبة من قبل المبحوثين، ومعرفة أكثر المواقع الاجتماعية التي تتشرها.

$$
\text { - - التوصل إلى أهم طرق مواجهة الأخبار الكاذبة من قبل المبحوثين. }
$$

منهج البحث وادواته: المنهج هو عبارة عن مجموعة من العمليات والخطوات الي يتبعها الباحث في ضبط ابعاد، مساعي و أسئلة وفرضيات البحث( زرواتي رشيد) ـوقد اعنمدت الباحثة على المنهج المسحي بشقيه التحليلي و الميداني لدراسة الظو اهر المرتبطة بمشكلة البحث وجذور ها وتطور ها، كونه المنهج الأكثر ملائمة للار اسات الوصفية. إذاً إن معالجة مثل هكذا موضوع يحتاج لمعرفة أهم المضامين المتداولة في الأخبار الكاذبة في مواقع الإعلام الاجتماعي وأنواعها وسبل مواجهتها من قبل المستخدمين، وكيف يتم التحقق منها.

مجتمع البحث وعيته: المقصود بمجتمع البحث "جميع عناصر ومفردات المشكلة أو الظاهرة قيد الدراسة، فهو يشمل الوحدات و الفئات التي تقع في إطار تعميمات البحث ونتائجه ". (عبد الله عبد الرحمن الكندري ومحمد احمد عبد الدايم) أما العينة " هي جزء من مجتمع البحث، و هي عدد من الحالات التي تؤخذ من المجتمع الأصلي، وتجمع منها البيانات بقصد در اسة خصائص ذللك المجتمع، ويمثل هذا الجزء النموذج الذي يجري عليه الباحث مجمل عمله ".( وجيه محجوب،2002) ففي الجانب التحليلي تم اختيار الصفحات التي تعالج وتكثف المضامين الكاذبة في مواقع الإعلام الاجتماعي ومنها، صفحة التقنية من أجل السلام ومنصة فتبينوا وتلك الصفحتين تحاول جاهدة في الكثف عن الأخبار الكاذبة والرجوع لمصادرها 
الحقيقة، أما الجانب الميداني تم اختيار شريحة من أساتذة كليات الإعلام في الجامعات العراقية ممن شاركوا في الدورات التدريبية للتربية الإعلامية الرقمية وذلك لمعرفتهم بآليات التحقق من المضامين الكاذبة أو الزائفة وسبل مو اجنها.

\section{حدود البحث ومجالاته}

المجال الزمانى: حددت الباحثة المجال الزماني لهذا البحث للمدة من 2020/7/1 إلى 2020/10/1 للار اسة التحليلية، وكان عام

$$
\text { 2020م هي الفترة التي أجريت فيها الإجر اءات الميدانية. }
$$

المجال المكاني: اختارت الباحثة صفحتي التقنية من أجل السلام يديرها شباب مختص بتكنولوجيا المعلومات والاتصال، ومنصة فتبينو المكافحة الأخبار الكاذبة /العربية.

$$
\text { للار اسة الميدانية: كليات و أقسام الإعلام في الجامعات العر اقية. }
$$

سابعًا : اختبار الصدق والثبات تم عرض استمارة التحليل والاستبانة ( إلكترونباً) على الخبراء *من نفس الاختصاص لتحكيمها وبعد إعادتها من قبلهم تم إجراء بعض التعديلات وحسب الملاحظات المَعطاة وكانت نسبة اتفاق الخبر اء على فقرات

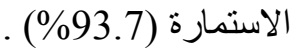

قياس الثبات: أما من ناحية قياس معامل الثبات قامت الباحثة بإجر اء التحليل بعد مدة من الزمن (الاتساق الزمني) حُددت بشهر لتكون نتائج التحليل وحسب معادلة هولستي (0.815) و هي نسبة تعتبر جيدة لدقة البيانات وثباتها.

وما يتعلق بالدر اسة المبدانية تم الاستعانة بطريقة re-test reliability إذا تقوم على إعادة الاختبار على مجموعة من أفراد العينة اثناء مدة زمنية و عادة ما تكون أسبو عين، بنسبة 10\%من المجموع الكلي للأفراد المبحوثين وتم توزيع الاستبانة مرة أخرى على البعض ممن أجابوا عليها في المرة الأولى ومطابقة إجابتهم مع الإجابة السابقة لهم إذا بلغت نسبة الثبات 88\% و هي نسبة جيدة تؤشر ثبات استمارة الاستبانة.

الار اسات السابقة:

$$
1 \text { - دراسة مها السيد بهنسي:2019 :( مها السيد بهنسي،2019) }
$$

اهتمت الدراسة ببحث دور مستخدمي الثبكات الاجتماعية في الكثف عن الأخبار الزائفة بهذه الثبكات والآليات التي يستخدمو ها في مواجهتها وربط ذلك بمدى توافر مهارات التربية الرقمية لدى المستخدمين وتوصل الباحثة إلى أن مهارات التربية الرقمية تزيد من قدرة المتلقي على التحقق من الأخبار الزائفة وكلما زاد نشاط الفرد الالكتروني زادت قدرته على 
التحقق من الأخبار بناء على مصادر المعلومات لايه سواء كانت شخصية أم مؤسسية، وأوضحت الدر اسة بأن هنالك وعي من قبل الافراد بموضوع الأخبار الكاذبة وقد ظهرت نتيجة تحديد سمات الأخبار تلك حيث تمثلت في عدم تمتع المصدر بالمصداقية و الخلط بين الحقائق والاكاذيب وعدم معرفة مصدر الخبر وتركيز الخبر على جوانب معينة وإغفال جوانب أخرى واختلاف العنوان مع المحتوى و عدم نشره في مو اقع أخرى.

$$
2 \text { - عبد الرزاق الدليمي 2018م:(عبد الرزاق محمد الدليمي،2018) }
$$

اهتمت الدراسة بمدى إدراك مدرسي الإعلام والصحفيين للأخبار المفبركة من حيث المفهوم والأهداف والأخطار، وكذللك بدو افع اعتماد الصحفيين الأردنيين ومدرسي الإعلام على الأخبار المفبركة في عملهم، وكيف يتعاملون معها.. قد بينت الدراسة بأن مدرسي الإعلام برون بأن الأخبار المفبركة تجعل الفرد في حيرة بين تصديق مضمونها وتكذبيه مما يؤثر على مصداقيته، كما وضحت بأن هنالك فروقات في فهم و إدراك الصحفيين للأخبار المفبركة من حيث المفهوم والأهداف والأخطار وكذلك بين مدرسي الإعلام تعود للمنصب الوظيفي لكل منهما.

$$
3 \text { - دراسة إيناس بوسعيدي2018م:( ايناس بوسعيدس،2018) }
$$

تحاول الدراسة انطلاقا من تغطية قناة الجزيرة للمشهد اليمني وتحديدا الأخبار المتدفقة عن اليمن عبر منصات الإعلام الاجتماعي البحث في آليات التحقق منها عبر سلاسل إنتاج الخبر بدءا من البحث عنه وصولاً إلى اعتماده وبثه حيث تدور أهمية البحث حول تصدر مخاوف اكتساح الأخبار الكاذبة للمشهد الإعلامي في ظل انخراط المؤسسات الإعلامية والصحفيين في اعتماد الإعلام الاجتماعي كمصادر لأخبار هم دون امتلاك المهار ات المناسبة للتحقق منها.

$$
\text { 4-محمد الراجي 2018م:( محمد الراجي،2018) }
$$

حاولت الدراسة عبر تحليل آليات صناعة الأخبار الكاذبة واستراتيجية محاصرة الرأي العام بالمحتوى البديل للقائم بفبركة الخبر، بوضع نموذج أسماه الباحث ( لولب الحصار المعلوماتي ) إذ تهتم الدراسة بكيفية صناعة الأخبار الكاذبة أو الزائفة لمحاصرة أو تطويق الر اي العام عبر التشويش و الاحتيال في المنصات الرقمية والوسائل الإعلامية بشكل عام وذلك من خلال اختراق المنصات المنافسة، ضخ المعلومات والبيانات المفبركة ( هجمة لولبية عاصفة) ومن ثم التسويق السياسي لخطاب المفبركين عبر الإعلام الاجتماعي أو التقليدي، للتأثير في الر أي العام معرفياً ونفسياً وسلوكياً. 5- منتصر مرعي وسام دبرلي وديانا لاريا 2017م : (مجمو عة باحثين،2017) 
جاء الكتاب كمساهمة في تطوير أساليب تعزز من قدرات الصحفيين في الاعتماد على المحتوى الذي ينتجة المواطن العادي و إعطاء منهج و أدوات للتثبت من صحة المحتوى من خلال تجارب عربية سواء كانت لمؤسسات إعلامية أو مواقع إعلامية إلكترونية أو اجتماعية على شبكة الإنترنت، إذ أتاح الكتاب الفرصة للعديد من الصحفيين العرب بالحديث عن تجاربهم في مجال البحث عن الأخبار عبر مواقع التو اصل الاجتماعي و أهم الطرق المعتمدة في التحقق منها.

\section{المبحث الأول : الدراسة النظرية}

اولاً: الخبر والخبر الكاذب والاشاعة "إن الخبر هو تقرير يصف في دقة وموضوعية حادثة أو و اقعة أو فكرة صحيحة تمس مصالح أكبر عدد من القر اء و هي تثير اهتمامهم بقدر ما تسهم في تنمية المجتمع وترقيته” ،" وهو وصف أو تقرير عن حدث لم يكن معروفًا عند الناس قبل جُمع بدقة من مصادر موثوق بصحتها". ( إسماعيل إبر اهيم،1998) و القيم الأخبارية هي العناصر التي يجب نوفرها كلها أو بعضها في الخبر لكي يمكن اعتباره خبر ا هناك من برى أن الدقة، الصدق، الموضوعية، سياسة الجريدة هي من عناصر الخبر، ولكنها تكون أقرب الى صفات الخبر من عناصره، لأن العنصر مهم جدا لوجود الثيء ولكن الصفة قد تكون أو لا تكون، فالدقة تعني أن يذكر الخبر الحقيقة كاملة وبدونها يكون الخبر ناقصاً وقد تكون صياغته بقصد أو بدون قصد، أما الموضو عية فهي عدم تحريف الخبر بالإضافة أو الحذف أو التلوين برأي المؤسسة الصحفية أو الصحفي نفسه وإذا فقد الخبر إحدى تلك الصفات بالإمكان أن نطلق عليه خبر كاذب أو زائف.( علي منعم

يعتبر الخبر هو الأساس الأول ( القاعدة) لكل ما يكتب وينشر من الفنون الصحفية الأخرى وعلى كاتبه تحري الصدق والأمانة في الحصول على الأخبار من مصادر ها الصحيحة ولا يمكن الاستهانة بنقله على أساس السبق الصحفي (عبد اللطيف حمزة )أو الحصول على الثهرة، فالصدق والدقة توءمة متلازمة بالنسبة للخبر ، وعدم توفر الدقة قد يهمل الخبر و لا يجد لله قراء أو لا تنشره أي صحيفة أو موقع، كون الخبر غبر الدقيق يؤثر على القراء وبالتالي على تشكيل الرأي العام بشكل سلبي حاله حال الخبر الغير صادق فالاقة واجبة من حيث حصول الخبر من مصادره الصحيحة كما هي مهمة في تشكيل مفرداته.

الخبر الإكتروني: مفهوم الخبر الإلكتروني يدل على الأخبار التي يتم بثها على المو اقع الإعلامية وعلى الثبكة بكافة مواقعها سواء الثخصية أو العامة أو شبكات التو اصل وتكون على مدار الساعة. تخضع هذه الأخبار في غالبية المواقع إلى عمليات تحديث مستمرة، لإضافة أية تفاصيل وتطورات جديدة إلى الحدث، وتزوده بالصور و الخلفيات، وبالإضافة إلى ربطها بالأحداث المتشابهة وقو اعد البيانات والمعلومات من خلال الروابط التشعبية، بمعنى آخر أنها أخبار تفاعلية تشاركية أضفت عليها التقنية 
المتجددة للمعلومات والاتصال هذه الميزات، لتكسر حكرا كان لقرون بيد الصحفيين ويصبح بإمكان المواطن العادي كتابة الخبر ونشره على موقعه الشخصي أو أي موقع يشترك به أو يسمح له بذلك.( عبد العزيز الثريف،2015)

الأخبار الكاذبة (الزائفة): في السنوات القليلة الماضية أصبحت الأخبار الكاذبة هي الكلمة الأكثر انتشار ا حتى تم اختيار ها من قبل قاموس" كولينز" كونها الكلمة الأكثر تاثير اً وحضورًا. فقد بدأ تعبير الأخبار الكاذبة بالانتشار وتكرر استخدامها من قبل الرئيس الأميركي دونالد نر امب في إطار تهجمه على وسائل الإعلام عام 2016 وموقفه من الأخبار التي تنشر ها والتي لا تتفق معه ويصفها بالمعادية.. و هذا لا يعني بان الأخبار الكاذبة هي وليدة استخدام الرئيس الأميركي في حملته الانتخابية أو بعدها ولكنها ظاهرة لها جذور ها القديمة فهي قديمة قدم الإنسانية. ففي الصحف التي تحترم نفسها وقراؤها وتحوز ثقتهم لا مكان للخبر الكاذب ينشر فوق صفحاتها وهذا ما ينطبق على بث الأخبار في القنوات التلفزيونية والإذاعية، فنشر مثل تلك الأخبار غير الصحيحة توقع الصحيفة أو المؤسسة الإعلامية في المحظور وتسعى جاهدة لتكذيب الخبر أن نُشر على صفحاتها أو تم أذاعته في بثها، مما يدفع بالمتلقي إلى تكذيب كل ما تنشره أو تبثه تلك المؤسسات الإعلامية وقد ينعتها البعض بالصحف الكاذبة أو القناة التي تبث أخبار كاذبة و غير موثوق بها.

وقد زاد من انتشار الأخبار الكاذبة وجود و انتشار مواقع الإعلام الاجتماعي التي أعطت المجال واسعاً أمام المتلقين بنشر ما يريدون بكل حرية سواء كان نصاً أو صورة أو فديو، إذ أخذت تللك الأخبار أشكالا ودوافعا جديدة لها تأثير ات بالغة الأهمية على أرض الو اقع حيث ساهم الفرد في صناعة و إنتاج تلك الأخبار وانتشار ها بشكل سريع فاقَ ما تنشره الوسائل التقليدية وما ينتجه الصحفيون.

و الأخبار الكاذبة تسمى الأخبار الزائفة أو المزيفة أو المخادعة وغير المهمة والأخبار غير الدقيقة. وهي معلومات قد تكون مضللة أو خاطئة أو ملفقة الهدف من نشر ها خداع القراء ودفحهم إلى الاعتقاد بأنها معلومات صحيحة وموثوقة، تنشر أما في الوسائل الاتصالية التقليدية أو في مواقع الإعلام الاجتماعي أو في المواقع الإلكترونية بشكل عام. كما تعرفه شبكة الصحافة الأخلاقية بأنه" خبر مختلق عمداً ينم نشره بقصد خداع طرف آخر وحثهُ على تصديق الأكاذيب أو التشكيك في الحقائق التي يمكن إثباتها"

$$
\text { تكمن خطورة الأخبار الكاذبة في عدة أبعاد وكما ذكر ها محمود أدهم وهي:( محمود ادهم،1987) }
$$

- اعتماد الجمهور القارئ على أخبار عارية من الصحة ليكون راية وبالتالي يجعله غير قادر على الحكم على الأحداث بالثكل الصحيح. 
- يصبح الفرد غير قادر على اتخاذ القرار الصائب نظراً للتشويش الحاصل لفكرهو عقله. - أي تحليل أو تقدير أو أحكام تستند على الخبر الكاذب تكون غير سليمة وهذا يؤثر بالتالي على القراء أنفسهم والرأي

$$
\text { العام بشكل أوسع. }
$$

- اعتماد وسائل الإعلام الأخرى على الخبر المكتوب قد يؤدي إلى خطورة تؤثر على الرأي العام فيما بعد. - نشر الأخبار الكاذبة وخاصة فيما يتعلق بالعلاقات الدولية يؤدي إلى أحداث سلبية كقطع العلاقات أو الوقيعة بين الثعوب.

الفرق بين الاشاعة والخبر الكاذب: اتفقت جميع المعاجم والقواميس على أن الإشاعة مصدر أشاع، فهي خبر مكذوب غير موثوف فيه وغير مؤكد ينتشر بين الناس أب انَتَرَر، وأشناع الخبر يعني نشَره وأذاعه أعلنه و أفثشاه وهو نبأ يذيع في الناس عن حادثة مو هومة وقعت أو يحتمل وقو عها. و أشّاع خبراً بين الناس بمعنى أذاعهُ وأشاع الثيء وبه أظهرهُ ونشرةً.( معجم المعاني) و هي فكرة معينة مرتبطة بو اقعة ما وسريان هذه الفكرة في مجتمع معين تحدد من حيث الزمان و المكان يغلب عليها إن لم يكن عدم الصحة فعلى الأقل الصحة الجزئية إذ تختلط بالأسطورة من جانب وبالنكتة أو الفكاهة من جانب آخر. (حميدة

كما يعرفها آخرون على أنها " أخبار مشكوك في صحتها ويتعذر التحقق من أصلها وتتعلق بموضوعات لها أهية لدى الموجهة إليهم ويؤدي تصديقهم أو نشر هم لها إلى إضعاف روحهم المعنوية) وكذللك بث خبر من مصدر ما في ظرف معين ولهذف ما ييتغيه المصدر دون علم الآخرين وانتشار هذا الخبر بين أفراد مجموعة معينة.( عبد العزيز محمد السدحان) وقد يُعرفها علماء الاجتماع والإعلام بأنها "عبارة عن نبأ أو حدث قادر على الانتشار والانتقال من شخص لآخر وقادر على زعزعة الر أي العام أو تجميده دون التثبُت منه".( عوض عز الرجال عفيفي)

وترتبط الإشاعة بالأزمات و الحروب و النكبات وتنشط في التحو لات الجوهرية سواء سياسية أم اجتماعية أو اقتصادية وربما عند اتخاذ قرارات مصيرية، إذا تنتشر في المجتمعات التي تعاني من ضعف الوصول إلى المعلومات وعدم القرة على امتلاكها والجهل بها. ومن خصائص الثائعات سهولة الانتشار والتنقل وتكون مبهمة وغير واضحة وتزدهر بوقت تكون المعلومات فيه قليلة حول الموضوع، وتحتوي على جزء بسيط من الحقيقة مما يجعل الناس بتقبلها وتتميز بقابلية التصديق و غير مشكوك بها خصوصا إذا ابتعدت عن التجريح و النقا.( مجموعة باحثين،2012) و الإشاعة ليست خبر ا مجردا فالخبر هو 
مجرد نقل للوقائع في شكل إعلام بينما الإشاعة هي نعليق على ذلك الخبر القصد منها تحقيق حالة نفسية معينة من التعبير عن حالة من حالات التوتر أو الاشباع أو التخلص من التوتر.( حميدة سميسم)

العلاقة بين مواقع التواصل الاجتماعى وانتثار الأخبار الكاذبة:ومن أهم صفات الأخبار في الإعلام الاجتماعي أنها تتميز عن الأخبار التي تنشر في وسائل الإعلام التقليدية كونها (مشُخصنة) بمعنى أن القارئ الإلكتروني اليوم يقرأ الأخبار التي يرغب بها ويشارك ما يحب ويعلق على الخبر الذي يريد ويتفاعل معه وكذلك يبعد عنه الأخبار الغير مرغوب بها ويختار ما يتو افق مع ميوله واتجاهاته إضافة الى ذللك أن الأخبار في الإعلام الاجتماعي هي أخبار تشاركية تفاعلية بمعنى ان المتلقي يساهم بشكل كبير في تبادل ونشر الأخبار اذ يفضل اكثرهم الأخبار الموجودة في مواقع التواصل الاجتماعي كونها بعيدة عن عين الرقيب وسلطوية الحكومات كما هي الوسائل التقليدية.( جمال الرزن،2018)

ونظر اً للتطورات التي لحقت تكنولوجيا الاتصال والمعلومات وما رافقها من تطور للرسالة الإعلامية والوسيلة والمرسل، فقد أتاحت تللك التطورات إلى إفساح المجال للفرد أن يبدي رأيه ويكتب ما يريد وينشر عبر المواقع التي يشترك فيها أو موقعه الثخصي (صفحته على الثبكات الاجتماعية)، بينما كانت حكراً على الصحفيين وازدادت البيانات والمعلومات وتزاحمت المو اقع بما ينشره المو اطن نظر اً للحرية التي يتمتع بها في نشر وتبادل ومشاركة المحتوى ولم بيقَ متلقياً سلبياً، فكان من بين تلك المعلومات ما هو غث وسمين ما هو كاذب وصادق ما هو موثوق به أو لا وبين ما هو حقيقي وزائف. إن نشر الأخبار الكاذبة ومشاركتها عبر مواقع الإعلام الاجتماعي غالباً ما يؤثر في تشكيل الرأي العام ويقوض التماسك الاجتماعي وربما يؤثر في سياسات الدول المتبعة وأمنها واستقرارها، فخطورنها لا تقتصر على الفرد و إنما يتعدى ذلك إلى تهديد الأمن المحلي للبلدان إذ أن نشر هكذا أخبار وتداولها بين الناس لا يُحمل الفرد أو الدول أو المجاميع إلى أي عبء مادي مما يجعله سلاحاً سهلاً في أيدي الجميع بعدما كان استخدامها بيد السلطات.

و إلى جانب ذلك فقد أكدت بعض الدراسات الأجنبية أن الأخبار الكاذبة والمضللة "باتت القضية الأشد حضوراً في التأثير على الإعلام و الاقتصاد و السياسة في غالبية دول العالم ففي دراسة استطلاعية سنوية جرت على 25 الف مواطن في 25 دولة من دول العالم لمركز مبادرة الحوكمة العالمية وبالتعاون مع مركز ipsos، والتي أجريت للمدة من 12-2018 الى 1-2019 أن أغلب الناس حصلوا على الأخبار الكاذبة من الإعلام الاجتماعي بنسبة 65\% وبنسبة 44\% من الإعلام التقليدي.( صالح مشارقة،2020) وتوصلت دراسة أشرف عليها باحثون من معهد ماساتشوستس للتقنية إلى أن الأخبار الكاذبة تتنتر على موقع (توتير) بشكل أسرع ويحث الناس عنها أكثر من الأخبار الحقيقية، وأرجع الباحثون ذلك إلى أن تلك الأخبار غالباً ما تكون غير 
مألوفة لذلك يميل الناس لمشاركة المعلومات غير المألوفة والمدهشة وكانت فرصة مشاركة الأخبار الكاذبة تصل إلى 70\% مقارنة بالأخبار الحقيقية.( ملخص لدر اسة حول الأخبار الزائفة،2018)

كما كثفت دراسة أجراها باحثُون في جامعة أكسفورد البريطانية أن القصص غير المرغوب فيها(الأخبار الكاذبة) على منصة الفيس بوك في أوروبا تتفوق بعدد المشاركات والإعجاب والتعليقات على الأخبار الاحتر افية في المصادر الإعلامية التقليدية الأخرى؛ ويرجع ذلك لسهولة التعرض لها وتبادلها بين الناس واستخدامها لعناصر التشويق و الكذب.

وفي المقابل فإن من أهم دوافع مشاركة وتبادل الأخبار الكاذبة هي ضعف ثقة الجمهور بما تبثه وسائل الإعلام الحكومية نظر اً لسيطرتها على المحتوى المنشور و عدم إتاحة المعلومات بشكل سريع، إضافة إلى عدم وجود الرقابة وغياب المُحاسبة، وزيادة عدد المنصات الاجتماعية والمواقع الإلكترونية التي تسمح للأفر اد بالتعبير بكل حرية ونقل ما يدور حوله من قضايا وأحداث، فضلاً عن الدور الذي تلعبه التقنيات الحديثة والذكاء الاصطناعي من خلال برامج المونتاج الخاص بالصور و الصوت ومقاطع الفيديو في التشوية والتلفيق و الفبركة وبر امج النشر التلقائي التي ساعدت في انتشار وتبادل المعلومات الكاذبة والتفاعل معها، ولا يمكن التغافل عن الدافع النفسي والعاطفي للفرد الذي يعزز من انتشار الأخبار الكاذبة من خلال ميوله واتجاهاته ومواقفه نحو القضايا.

وتسعى الثركات الكبرى التي تَملك منصات اجتماعية بمر اقبة شبكاتها بقدر أكبر ونرفع الأخبار الكاذبة بما في ذلك التي تروج لها شبكات آلية * ، للحد من انتشار الأخبار الزائفة والمعلومات المفبركة وتوفير سياقات أكبر للأخبار، وإغلاق حسابات الدعاية المدعومة من الدول في إطار التصدي لهذه الظاهرة ومو اجهة ترويجيها، فيما سعت بعض الحكومات إلى وضع لوائح وقو اعد حكومية لمراقبة المحتوى المتداول عبر شبكة الإنترنت وتدفق المعلومات على مواقع الإعلام الاجتماعي ومعالجة الأخبار الكاذبة، كما فعلت إندونيسيا والفلبين ودول أوروبية مثل ألمانيا لتشرع قوانين تفرض عقوبات وغرامات مالية ( للأفراد و الثركات ) لكل من ينشر أخبار أو معلومات مضللة تساعد على العنف والانقسام والكر اهية و الذعر و العنصرية. تصنيفات الأخبار الكاذبة: قسم الباحثون في دراساتهم الإعلامية، الأخبار و المعلومات الكاذبة إلى عدة أقسام منها وكما ذكرتها در اسة واردل وحسين دير اخشان هناك ثلاثة أنواع من المعلومات: - أخبار خاطئة: معلومات خاطئة لا نهدف إلى الإيذاء كالتسرع في النشر، مجار اة السبق الصحفي، عدم التحقق من معلو ماتها ومصادر ها. 
- أخبار مزيفة: معلومات مَضللة تكون خاطئة وتسبب الأذى، تحمل مضمون مخادع أو متلاعب به أو مفبرك وتم التلاعب بها وتعديلها بشكل مقصود.

- أخبار مخادعة: معلومات غير حقيقية القصد منها أحداث الأذى مثل الترسيبات والتحرش والكر اهية متلاعب بها هدفها خداع الجمهور والناثير في مو اقفه.( صالح مشارقة) وحدد مجلس التريية الإعلامية الأخبار الكاذبة بستة أنواع وهي:(مها السيد بهني،2019)

1 ـ أخبار السخرية، والتي تستخدم الفكاهة وتبالغ في السخرية القصد منها التأثنر على الجمهور وخداعه رغم أن البعض لا يأخذ مثل تلك الأخبار بمحمل من الجد. 2 - المحتوى المضلل، ويتم استخدام بعض الحقائق ولكنها تفسر بشكل مختلف عن الو اقع بما يتفق مع وجهة نظر كاتبها وأهدافه. 3 - الربط الخاطئ: عندما يكون العنوان لا يشابه المحتوى الكَقدم ويستخدم لزيادة عدد القراء ولمزيد من الأرباح. 4 - السياق الخاطئ يستخدم هذا النوع للاحتيال على الجمهور. 5 - المحتوى المتلاعب به: يتم فيها التعديل و التغير في التفاصيل. 6 ـ المحتوى الملفق: ويكون المضمون غير صحيح تماما ويتم اختلاقه وهو شديد الخطورة إذا ما تم تصديقه من قبل الجمهور.

و هنالك تصنيف آخر للأخبار الكاذبة حسب ما ذكرتها بعض الدراسات الأجنبية منها أخبار السخرية، الأخبار المتحيزة، نظرية المؤامرة، طو احن الثائعات، العلم الزائف، أخبار الكر اهية، الأخبار المَضللة، الأخبار السياسية.( مها السيد بهنسي) ولتجنب الوقوع في فخ الأخبار الكاذبة هناك بعض الارشادات على القراء اتباعها ومن تلك الارشادات هى :*

- ضرورة التشكيك في عنوان الخبر، كلما كان غير منطقي وغريب يفضل عدم الوثوق به. - التحري من ر ابط الخبر في الموقع لوجود مواقع مزيفة تحاكي المواقع الأصلية. - التحقق من مصدر الأخبار ويفضل أن تكون مصادر مجربة وتتصف بالمصداقية. - تحري تنسيق الخبر، فالخبر الكاذب يحمل أخطاء لغوية وغير منسق. - التدقيق في الصور و الفيديو هات المنشورة، إذا تنشر معظمها من غير سياقها. 
- تحري تاريخ الخبر ، فقد ينشر مضمون لخبر حصل من فترة ماضية. - التأكد من الثو اهد المقدمة في الخبر و المصادر المعتمدة. - التأكد من نشر الخبر في أكثر من مصدر، فتعدد المصادر بعطي موثوقية للخبر . - التأكد من أن الخبر ليس للسخرية أو لمزحة، و هذا يكون واضح من سياق الخبر تفاصيله و اللغة المستخدمة. - ضرورة التحري من منطقية الخبر و عدم نشر خبر لم بتم التأكد من مصداقيته.( لينا عجيلات)

\section{المبحث الثانى: الدراسة المسحية (التحليلية والميدانية)}

أ - الار اسلة التحليلية لصفحة التقنية من أجل السلام (عر اقي) ومنصة فتبينو المكافحة الأخبار الكاذبة ( عربي/ سوري)، تم إخضاع جميع موضوعات (حصر شامل) موقعي التقنية من أجل السلام والذي يديره بعض الثباب العراقي المتخصص في مجال التقنية و هي صفحة تمنح صورة أوضح لمصداقية ما ينشر في مواقع التواصل الاجتماعي في العراق ومحيطه بالإضافة إلى الأمن الرقمي، ومنصة فتبينوا و هي منصّة عربيّة مستقلة، انطلقت عام 2014، متخصصة في مجال التحقق من المعلومات، "تهدف إلى تنقية المحتوى العربي من الأخبار الكاذبة"، لمدة ثلاثة أشهر لمعرفة أهم المضامين الأخبار الكاذبة التي تكثفها في مواقع الإعلام الاجتماعي للفترة من 1-7 الى 1-10-2020م. إذ تم اختيار وحدة الموضوع ( الفكرة) كوحدة تحليلية وقسمت الباحثة فئات التحليل إلى رئيسية وفرعية تعنى بمضمون الموضو عات(ماذا قيل؟) و الثكل (كيف قيل؟). ومن أهم النتائج التي توصلت إليها الباحثة من خلال تحليل

$$
\text { الموضو عات في الموقعين هي: }
$$

اولاًا: فئة ماذا قيل؟

جدول (1): يبين الفئات الرئيسية في موقع التقنية من أجل السلام ومنصة فتبينوا

\begin{tabular}{|c|c|c|c|c|c|c|}
\hline \multicolumn{3}{|c|}{ فتبينوا } & \multicolumn{4}{|c|}{ التقتية من أجل السلام } \\
\hline المرتبة & $\%$ & ك5 & المرتبة & $\%$ & ك5 & المضامين \\
\hline الثالثة & 8.63 & 12 & الثانية & 19.33 & 35 & السياسية \\
\hline الثالثة الثة & 8.63 & 12 & الاولى & 23.20 & 42 & الأمنية \\
\hline الر ابعة & 5.03 & 7 & السادسة & 8.28 & 15 & الاجتماعية \\
\hline السادسة & 2.15 & 3 & السابعة & 4.97 & 9 & الاقتصادية \\
\hline الثانية & 30.21 & 42 & السادسة & 8.28 & 15 & الصحية \\
\hline السادسة & 2.15 & 3 & الخامسة & 9.39 & 17 & الفنية \\
\hline الخامسة & 2.87 & 4 & الثنامنة & 2.20 & 4 & الرياضية \\
\hline الثالثة & 8.63 & 12 & الر ابعة & 9.94 & 18 & الدينية \\
\hline الأولى & 31.65 & 44 & الثالثة & 14.36 & 26 & منو عة \\
\hline & $* \% 100$ & 139 & & $\% 100$ & 181 & مجموع \\
\hline
\end{tabular}

*رقم النسب المئوية يتر اوح تقريبا بين 99.98 و 101\% 
من خلال تحليل البيانات في جدول رقم (1) نرى بأن أغلب مضامين الأخبار الكاذبة المنشورة في مواقع الإعلام الاجتماعي والتي أثبت موقع التقنية عدم مصداقيتها وكثفها، هي الأمنية بواقع 23.20\% وتتعلق بالعمليات الإرهابية داخل العراق والأوضاع الأمنية والعسكرية وكذلك الموضوعات السياسية بنسبة 19.33\%، فيما كانت أهم المضامين التي تم كثفها في منصة فتبينو ا هي المضامين المتنوعة والمتعلقة بالحو ادث الطبيعية والتقنيات الحديثة والتراث العربي والعالمي بو اقع 31.65\% و الموضو عات الصحية بنسبة 30.21\% وهذا يدل على أن اهتمام الموقعين بكثف الأخبار مختلف نظر الطبيعة عمل وأهداف كل منهما. فالتقنية من أجل السلام حاولت أن تكشف أغلب الأخبار المتعلقة بالواقع المحلي (العر اقي) وما يتعلق بالقضايا الأمنية و السياسية لأهميتها بالنسبة للثار ع العر اقي وقدر ها في التأثير على الرأي العام، في حين كانت الموضوعات المنوعة والصحية هي الغالبة على مضامين منصة فتبينو اكونها منصة تكثف وتبين الأخبار الكاذبة على الساحة العالمية والعربية أكثر من تركيز ها على المحلي.

جدول (2): يبين الفئات الفرعية للفئة الرئيسية للمضامين السياسية

\begin{tabular}{|c|c|c|c|c|}
\hline \multicolumn{2}{|c|}{ فتبينوا } & \multicolumn{3}{|c|}{ التقتية من اجل السلام } \\
\hline$\%$ & ك5 & $\%$ & ك & المضامين السياسية \\
\hline 75 & 9 & 65.71 & 23 & شخصيات سياسية \\
\hline 8.33 & 1 & 11.42 & 4 & ل رئاسة وبرلمان \\
\hline 8.33 & 1 & 5.71 & 2 & وزارات حكومية \\
\hline 8.33 & 1 & 17.14 & 6 & شُؤون دبلوماسبية \\
\hline \%99.98 & 12 & \%99.98 & 35 & المجموع \\
\hline
\end{tabular}

في جدول رقم (2) والخاص بالفئة الفرعية للفئة الرئيسية المضامين السياسية فقد كثفت صفحة التقنية من أجل السلام عدة أخبار كاذبة تمحورت حول شخصيات سياسية عر اقية بنسبة 65.71\% من مضامين الأخبار السياسية، وهذا أيضا ما كثفته منصة فتبينوا إذ كانت أهم الموضوعات السياسية المتداولة حول الثخصيات الحكومية بنسبة 75\%. و هذا يدل على أن أغلب الأخبار السياسية الكاذبة تتمحور حول الثخصيات التي تدير دفة الحكم وتتعلق بها. جدول (3): يبين الفئات الفرعية للفئة الرئيسية الأمنية

\begin{tabular}{|c|c|c|c|c|}
\hline \multicolumn{2}{|c|}{ فتبينوا } & \multicolumn{3}{|c|}{ التقتية من اجل السلام } \\
\hline$\%$ & 5 & $\%$ & ك & المضامين الأمنية \\
\hline & 0 & 14.28 & 6 & مؤسسات وشخصيات امنية \\
\hline 16.66 & 2 & 9.52 & 4 & عمليات إرهابية \\
\hline 83.33 & 10 & 57.14 & 24 & وضع امني \\
\hline & 0 & 11.90 & 5 & تظاهر ات شعبية \\
\hline & 0 & 7.14 & 3 & ثُؤون عسكرية \\
\hline$\% 99.99$ & 12 & $\% 99.98$ & 42 & المجموع \\
\hline
\end{tabular}

فيما يتعلق بالفئات الفرعية للفئة الرئيسية الخاصة بالموضوعات الأمنية، ففي جدول رقم (3) يتبين أن أكثر المضامين التي تداولتها مو اقع الإعلام الاجتماعي الكاذبة منعلقة بالأوضاع الأمنية في العراق والعالم العربي والعالمي مثل " خبر شن القوات 
الأميركية لتنفيذ غار ات جوية ضد الميليشيات العراقية، تصريح لجهاز مكافحة الإر هاب حول اختطاف الناشط سجاد العر اقي، فديو لعشائر تحاصر جهاز مكافحة الإرهاب وغير ها " فكانت نسبتها في موقع التقنية من أجل السلام 57.14\% من مجمل الأخبار الأمنية الكاذبة و83.33\% في منصة فتبينوا وكانت أغلبها تتعلق بالأوضاع الأمنية في لبنان بعد انفجار مرفأ بيروت.

$$
\text { جدول (4): يبين الفئات الفرعية للفئة الرئيسية الاقتصادية }
$$

\begin{tabular}{|c|c|c|c|c|}
\hline \multicolumn{2}{|c|}{ فتبينوا } & \multicolumn{3}{|c|}{ التقتية من اجل السلام } \\
\hline$\%$ & ك5 & $\%$ & ك & المضامين الاقتصادية \\
\hline 66.66 & 2 & 44.44 & 4 & مشاريع تنموية وصناعية \\
\hline & & 22.22 & 2 & شؤون وظيفية \\
\hline & & 11.11 & 1 & شؤون نفطية \\
\hline 33.33 & 1 & 22.22 & 2 & أسواق وعملات \\
\hline$\% 99.99$ & 3 & $\% 99.99$ & 9 & المجموع \\
\hline
\end{tabular}

أما المضامين الاقتصادية فكما مبين بجدول رقم (4) حازت الموضوعات الخاصة بالمشاريع التنموية والصناعية على نسبة أكبر من الفئات الأخرى في مضامين الأخبار الاقتصادية الكاذبة المنشورة في مواقع الإعلام الاجتماعي، فكانت هناك 4 موضوعات مثل " تخفيض سعر قنينة الغاز ولتر البزين، وجود 30مليار دينار في منزل المدير التنفيذي لشركة كي كارد إعطاء 30 الف راتب بدل البطاقة التموينية وغبر ها" بنسبة 44.44\% في صفحة التقنية من أجل السلام وموضو عان في منصة فتبينوا بنسبة 66.66\%.وكانت بقية الموضوعات نتناول الأوضاع المعيشية وأسعار العملات ورواتب الموظفين وشؤون اقتصادية منل" مصنع صيني يصنع قصصانا كطلبية لأمريكا عليها عبارة قاطعوا الصين، سيارات للشركات المستوردة من

$$
\text { الخارج جديدة صفر كم بمرفأ بيروت المدمر". }
$$

\begin{tabular}{|c|c|c|c|c|}
\hline \multicolumn{2}{|c|}{ فتبينوا } & \multicolumn{3}{|c|}{ التقتية من اجل السلام } \\
\hline$\%$ & 5) & $\%$ & 5) & المضامين الصحية \\
\hline 45.23 & 19 & 33.33 & 5 & فايروس كورونا \\
\hline 33.33 & 14 & & 0 & وصفات طبية \\
\hline 19.04 & 8 & 13.33 & 2 & امراض وعلاجات \\
\hline 8.33 & 1 & & 0 & شخصيات طبية \\
\hline & 0 & 53.33 & 8 & مؤسسات صحية \\
\hline$\% 99.99$ & 42 & $\% 99.99$ & 15 & المجموع \\
\hline
\end{tabular}

جدول (5): يبين الفئات الفر عية للفئة الرئيسية الصحية

في جدول رقم (5) والذي يتتاول الفئات الفرعية للفئة الرئيسية للمضامين الصحية، فقد تبين أن أكثر الأخبار الكاذبة التي تم كثفها، تتضمن سوء خدمات المؤسسات الصحية وخاصة المحلية هي الأكثر تداول بين الجمهور في مواقع الإعلام الاجتماعي كما بينه موقع التقنية من أجل السلام بنسبة 53.33\% وكانت المضامين الأخرى تتعلق بفايروس كورونا خاصة العلاجات و اللقاحات مثل" الكثف عن أن فايروس كورونا لا ينتقل بالملامسة وسيعود كل شي مثل ما كان، توفير لقاحات نهاية السنة 
2020. أما في منصة فتبينو ا والتي كانت مضامينها تأخذ بُعدأ عالمباً كثفت الأخبار الكاذبة التي تضمنت العلاجات و اللقاحات وتعليمات السلامة و النظافة الخاصة بفايروس كورونا لتنبيه المتلقين حول زيف ما ينقل حول هذا المرض وكانت بنسبة 45.23\% في حين ركزت على الأخبار الكاذبة الأخرى التي تتعلق بالوصفات الطبية الخاطئة وبعض العلاجات مثل "التنفس عبر الكمامة يؤدي الى نقص في الأوكسجين، شرب الماء دفعة واحدة يتسبب بتليف الكبد" جدول (6): يبين الفئات الفرعية للفئة الرئيسية المضامين الاجتماعية

\begin{tabular}{|c|c|c|c|c|}
\hline \multicolumn{2}{|c|}{ فتبينوا } & \multicolumn{3}{|c|}{ التقتية من اجل السلام } \\
\hline$\%$ & 5 & $\%$ & ك5 & المضامين الاجتماعية \\
\hline 28.57 & 2 & 40 & 6 & عنف اسري \\
\hline 42.85 & 3 & 6.66 & 1 & اعراف اجتماعية \\
\hline & 0 & 6.66 & 1 & مؤسسات ومنظمات اجتماعية \\
\hline & 0 & 26.66 & 4 & شؤون عائلية \\
\hline 28.57 & 2 & 20 & 3 & شؤون تربوية \\
\hline$\% 99.99$ & 7 & $\% 99.98$ & 15 & المجموع \\
\hline
\end{tabular}

المضامين الاجتماعية كان لها حصة من الأخبار الكاذبة والتي يتداولها الجمهور في مو اقع الإعلام الاجتماعي فكما موضح في جدول رقم (6) تبين أن أهم المضامين الاجتماعية التي تم كثفها تتعلق بالعنف الأسري بين الأزواج أو الأولاد وآبائهم مثل"خبر ضرب امر أة لزوجها بطابوكة، رجل يقوم بعَض خشم زوجته بسبب تبديل قنينة غاز، زوجة تقوم بقتل زوجها وتقطيعه ونوزيعه على شكل ثو اب" بنسبة 40\% ونوزعت باقي المضامين على الثؤون العائلية والتربوية في موقع التقنية من أجل السلام. أما في منصة فتبينوا كان أغلب الأخبار الكاذبة التي تم كثفها تتناول الأعر اف الاجتماعية مثل "بيروت المذبوحة، اختفاء القطط في عيد الأضحى، ساثشا هيرما صائد الأفاعي ومقتل زوجته " بنسبة 42.85\%. جدول (7): بيين الفئات الفرعية للفئة الرئيسية للمضامين الدينية

\begin{tabular}{|c|c|c|c|c|}
\hline \multicolumn{2}{|c|}{ فتبينوا } & \multicolumn{3}{|c|}{ التقتية من اجل السلام } \\
\hline$\%$ & 5 & $\%$ & 5 & المضامين الدينية \\
\hline 41.66 & 5 & 66.66 & 12 & ثخصيات دينية \\
\hline 50 & 6 & 33.33 & 6 & ثـعائر واعراف دينية \\
\hline 8.33 & 1 & & 0 & واريخ دينية \\
\hline$\% 99.99$ & 12 & $\% 99.99$ & 18 & المجموع \\
\hline
\end{tabular}

في جدول (7) الخاص بالفئات الفرعية للفئة الرئيسية للمضامين الدينية، كما موضح فإن أكثر الأخبار الكاذبة كانت تدور حول الثخصيات الدينية خاصة المحلية التي تم كثفها من قبل موقع التقنية من أجل السلام مثل " صورة للسيد محمد صادق الصدر وأولاده، إصابة باسم الكربلائي، اغتبال الثيخ أمير القريشي وغير ها " بنسبة 66.66\% فيما تناول أخرى شعائر و أعراف دينية مثل " أحياء أيام عاشوراء من قبل اليزيدين ". أما منصة فتبينوا فكانت أغلب الأخبار الكاذبة تركز على الأعراف و الطقوس الدينية مثل " آخر اختراعات كهنة الدين المسيحي لإتمام طقوس المعمودية في زمن الكورونا، حكم بالإعدام بالحرق 
بالنار بسبب قتل بقرة في الهند" بنسبة 50\% بينما ما يتعلق بالثخصيات الدينية كان بنسبة اقل 41.66\%مثل " خبر وفاة أمام

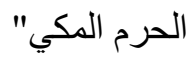
جدول (8): يبين الفئات الفرعية للفئة الرئيسية للمضامين الفنية

\begin{tabular}{|c|c|c|c|c|}
\hline \multicolumn{2}{|c|}{ فتبينوا } & \multicolumn{3}{|c|}{ التقتية من اجل السلام } \\
\hline$\%$ & ك & $\%$ & ك5 & المضامين الفنية \\
\hline 33.33 & 1 & 17.64 & 3 & شخصيات فنية \\
\hline 66.66 & 2 & 11.76 & 2 & اعمال فنية \\
\hline & 0 & 11.76 & 2 & مؤسسات فنية وثثافية \\
\hline & 0 & 58.82 & 10 & اخبار الوفيات \\
\hline$\% 99.99$ & 3 & \%99.98 & 17 & المجموع \\
\hline
\end{tabular}

أما المضامين الفنية التي تتاولتها الأخبار الكاذبة في مواقع الإعلام الاجتماعي كما موضح بالجدول أعلاه، فقد بين موقع التقنية من أجل السلام بأن أغلب الأخبار الكاذبة تتعلق بإثاعة وفاة الفنانين على الساحة المحلية والعربية مثل وفاة الثاعر عادل محسن وفاة الفنان محمود ياسين وفاة الفنانة ميلاد سري وفيروز و غير ها بنسبة 58.82\%، بينما كان النسبة جدا قليلة في منصة فتبينو ا بتكرار 3 موضوعات، ركزت أحدها على التصميم الفني "لمطار دبي الجديد وهو قيد الإنجاز " جدول (9): يبين الفئات الفرعية للفئة الرئيسية للمضامين الرياضية

\begin{tabular}{|c|c|c|c|c|}
\hline \multicolumn{2}{|c|}{ فتبينوا } & \multicolumn{3}{|c|}{ التقتية من اجل السلام } \\
\hline$\%$ & ك & $\%$ & ك & المضامين الرياضية \\
\hline 100 & 4 & 75 & 3 & شخصيات رياضية \\
\hline & 0 & 25 & 1 & مباريات والعاب \\
\hline$\% 100$ & 4 & $\% 100$ & 4 & المجموع \\
\hline
\end{tabular}

كانت حصة المضامين الرياضية قليلة من الأخبار الكاذبة في مو اقع الإعلام الاجتماعي في الموقعين فقد كثف عن وجود 4 موضو عات لكل منهما تتناول الشخصيات الرياضية مثل" فتح قنوات bein مجانا لمدة عام من قبل ناصر الخليفي " فيما كان هناك خبر كاذب واحد حول "نحت فريق بايرن ميونخ النتيجة التاريخية على جدار متحفه الخاص" وفي منصة فنبينو اكثفت عن الأخبار المتعلقة بالثخصيات الرياضية مثل "ثمن انتقال اللاعب راكيتيتش إلى اثبيلية كان 1.5 مليون يورو، صورة للمو هوبة مكة محمد صلاح عمر ها 5سنوات وغير ها" 
جدول (10): يبين الفئات الفرعية للفئة الرئيسية للمضامين المنوعة

\begin{tabular}{|c|c|c|c|c|}
\hline \multicolumn{2}{|c|}{ فتبينوا } & \multicolumn{3}{|c|}{ التقتية من اجل السلام } \\
\hline$\%$ & 5 & $\%$ & ك & المضامين المنوعة \\
\hline 52.27 & 23 & 30.76 & 8 & كوارث طبيعية \\
\hline 4.54 & 2 & 46.15 & ف12 & ترفية وسخرية \\
\hline 15.90 & 7 & 15.38 & 4 & تاريخ وتراث \\
\hline 25 & 11 & 7.69 & 2 & تقتيات حليثة \\
\hline 2.27 & 1 & & 0 & حكم واقوال \\
\hline$\% 99.98$ & 44 & $\% 99.98$ & 26 & المجموع \\
\hline
\end{tabular}

فيما يتعلق بالمضامين المتنوعة للإخبار الكاذبة في مواقع الإعلام الاجتماعي حصلت منصة فتبينوا على نسب أعلى في الكثف عن المضامين تللك أكثر من موقع التقنية من أجل السلام وذلك لطبيعة عمل كل منهما، إذ كانت معظم المضامين التي تم كثفها في موقع التقنية على أخبار السخرية والترفيه منل " السخرية من بعض الثخصيات السياسية والإعلامية وكذلك موضوعات تتعلق بأثخاص عاديين وبأفعال تثير الضحك والتعجب "طالب أميركي يضع مسهل لحيوان في عصبر للمدعوين في حفل نكريم، عراقي يصبغ كلبه مثل النمر، شراء قصر في جزيرة بميلغ 50 ألف دولار بينما كانت هناك بعض الأخبار تنتاول الكوارث الطبيعية كتشقق الأرض في بادية النجف. أما منصة فتبينوا فقد كشفت عن مضامين للأخبار الكاذبة تتناول الكوارث الطبيعية بنسبة 52.27\% مثل الأخبار المتعلقة بفيضان السودان والسبول التي تعرضت لها "صوت الحرائق والنيران في غابات سوريا، تمساح يهاجم المارة في شوارع السودان بسبب الفيضان". جدول (11): يبين الفئة الرئيسية للمجال الجغر افي للأخبار الكاذبة المنشورة في مواقع الإعلام الاجتماعي

\begin{tabular}{|c|c|c|c|c|}
\hline \multicolumn{2}{|c|}{ فتبينوا } & \multicolumn{3}{|c|}{ التقتية من اجل السلام } \\
\hline$\%$ & ك5 & $\%$ & 5) & المجال الجغرافي \\
\hline 3.59 & 5 & 61.32 & 111 & محلي \\
\hline 38.12 & 53 & 23.20 & 42 & عربي \\
\hline 47.48 & 66 & 15.46 & 28 & عالمي \\
\hline 10.79 & 15 & & 0 & غير معروف الجهة \\
\hline$\% 99.98$ & 139 & $\% 99.98$ & 181 & المجموع \\
\hline
\end{tabular}

في جدول رقم (11) كانت أغلب المضامين التي تناولتها الأخبار الكاذبة والتي تم كثفها في موقع التقنية من أجل السلام هي أخبار محلية من داخل العراق ومدنه بنسبة 61.32\% بينما كانت الأخبار المتعلقة بالبلدان العربية بنسبة 42\% و العالمية بنسبة 15.46\%، بينما منصة فتبينوا كانت الأخبار التي كثفتها وبينت أنها كاذبة تتعلق بالثأن العالمي بنسبة أكثر بلغت 47.48\% وبعدها الثأن العربي بنسبة 38.12\% و هنالك أخبار لبس لها أي جهة أو مجال جغر افي بنسبة 10.79\%. 
جدول (12): يبين الفئة الرئيسية لتصنيفات الأخبار الكاذبة المنشورة في مواقع الإعلام الاجتماعي

\begin{tabular}{|c|c|c|c|c|}
\hline \multicolumn{2}{|c|}{ فتبينوا } & \multicolumn{3}{|c|}{ التقتية من اجل السلام } \\
\hline$\%$ & 5 & $\%$ & ك5 & صنيفات الأخبار \\
\hline 42.44 & 59 & 37.56 & 68 & خبر مفبرك \\
\hline 35.97 & 50 & 34.25 & 62 & خبر مضلل \\
\hline 14.38 & 20 & 18.23 & 33 & طواحن الشائعات \\
\hline 0.71 & 1 & 2.20 & 4 & خبر متحيز \\
\hline 0.71 & 1 & 1.65 & 3 & عنصر المؤامرة \\
\hline 5.75 & 8 & 6.07 & 11 & مضمون السخرية \\
\hline$\% 99.96$ & 139 & $\% 99.96$ & 181 & المجموع \\
\hline
\end{tabular}

من ناحية تصنيف الأخبار الكاذبة فكما موضح في جدول رقم (12) تبين أن أغلب الأخبار التي ينداولها الجمهور عبر مواقع الإعلام الاجتماعي هي أخبار مفبركة فهي أخبار غير صحيحة تلفق ويتم اختلاقها لخداع الجمهور وتعتبر من أكثر الأخبار تداولاً لأن المتلقي يصدق بها ويسعى لتداولها خصوصـا إذا كان يتعرض لها للمرة الأولى. إذ كانت نسبة تللك الأخبار التي كثفها موقع التقنية 37.56\% بينما منصة فتبينو ا كانت بنسبة 42.44\% أما الأخبار المضللة التي تعطي إنصاف الحقائق كأن يكون العنوان كاذبا والمضمون حقيقة أو يكون مبالغا فيه أو خادع بنسبة 34.25\% في موقع التقنية و35.97\% في منصة فتبينو ا. وبعدها تأتي أخبار الثائعات التي تتعلق غالبا بوفاة إحدى الثخصيات البارزة سياسية أو فنية أو رياضية أو إصابتها بفايروس كورونا بنسبة 18.23\% في موقع التقنية و14.38\% في منصة فتبينو ا. أما المضامين الساخرة فقد كانت بنسبة 6.07\% في موقع التقنية و5.75 في منصة فتبينو اوكانت هناك بعض الأخبار المتداولة تتضمن التحبز لجهة سياسية أو دينية أو تتضمن عنصر المؤامرة مثل تهريب النفط العر اقي إلى إيران ومنع الحوثين بمرور ناقلات النفط إلى اليمن وغير ها.

\section{ثُانيا: كيف قيل؟ وتُعنى بالثكل كيف تم نشر الأخبار الكاذبة؟}

جدول (13): يبين الفئة الرئيسية لنوع الوسائط المتعددة المستخدمة في مضامين الأخبار الكاذبة

\begin{tabular}{|c|c|c|c|c|}
\hline \multicolumn{2}{|c|}{ فتبينوا } & \multicolumn{3}{|c|}{ التقتية من اجل السلام } \\
\hline$\%$ & ك & $\%$ & ك5 & عناصر الوسائط \\
\hline 5.75 & 8 & 12.15 & 22 & استخدام صورة \\
\hline 54.67 & 76 & 41.43 & 75 & صورة + نص \\
\hline 7.19 & 10 & 13.81 & 25 & فيديو \\
\hline 22.30 & 31 & 12.15 & 22 & فيديو+ نص \\
\hline 10.07 & 14 & 20.44 & 37 & نص فقط \\
\hline$\% 99.98$ & 139 & $\% 99.98$ & 181 & 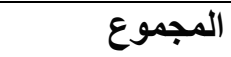 \\
\hline
\end{tabular}


أغلب الأخبار المتداولة تحوي على وسيط أو وسيطين لنشر ها وتناقلها بين الجمهور ومنها ما يكون نص أو صورة أو فيديو أو نص وصورة أو فيديو ونص وجميعها من خلال التقنية الحديثة يمن التلاعب في محتواها، أغلب الأخبار الكاذبة التي تداولها الجمهور حسب ما موضح في جدول رقم (13) كانت على شكل نص وصورة بنسبة 41.45\% في موقع التقنية و 54.67\% في منصة فتبينو ا. وكثف موقع التقنية الأخبار النصية وتوضيحها للمتلقين بنسبة 20.44\% فيما كان شكل النص مرفق بفيديو هو أغلب الأخبار التي كثفتها منصة فتبينوا بنسبة 22.30\%. وكان هناك أخبار مصورة وفيديوهات تم التناعب بها وتزيفيها لغرض تداولها ونشر ها على أوسع نطاق. جدول (14): يبين الفئة الرئيسية لنوع الموقع الذي نشر الأخبار الكاذبة في مواقع الإعلام الاجتماعي

\begin{tabular}{|c|c|c|c|c|}
\hline \multicolumn{2}{|c|}{ فتبينوا } & \multicolumn{3}{|c|}{ التقتية من اجل السلام } \\
\hline$\%$ & ك & $\%$ & 5 & نوع الموقع \\
\hline 34.53 & 48 & 35.35 & 64 & شخصي \\
\hline 58.27 & 81 & 39.77 & 72 & عام \\
\hline 7.19 & 10 & 24.86 & 45 & اعلامي \\
\hline$\% 99.98$ & 139 & $\% 99.98$ & 181 & المجموع \\
\hline
\end{tabular}

في جدول رقم (14) تبين أن هناك عدة أنواع من المو اقع تتداول الأخبار الكاذبة منها الثخصية ومنها مو اقع عامة ومنها مو اقع إعلامية لمؤسسات تلفزيونية وصحفية وأخبارية، كانت المواقع العامة هي الغالبة التي تنشر الأخبار الكاذبة في الموقعين بنسبة 39.77\% في موقع التقنية و58.27\% في منصة فتبينوا منل موقع (عرب أمريكا، أحداث كركوك الآن، بغداد دار السلام، بغداد، دلة عر اقية، الرواد السياسي، حشاشة بغداد، النجف مدينتي، ذكريات جيل الطيبين.. و غير ها) تم رصدها في موقع التقنية و (عجائب و غر ائب الدنيا، هل تعلم، صدى البلد، سويداء دار التراث، أسرار الثفاء بالاعثاب، وغير ها) في منصة فتبينوا. أما المو اقع الثخصية فكان لها دور في نشر الأخبار الكاذبة بنسبة 35.35\% تم كثفها في موقع التقنية و 34.53\% في منصة فتبينو ا. و لا يمكن إغفال المو اقع الإعلامية ودور ها في نشر الأخبار الكاذبة وعدم التحقق منها وسر عة نشر ها مثل موقع (شبكة العراق نيوز، شبكة العراق الأخبارية، قناة الرصافة الفضائية، انقاذ الثقافة العر اقية، الإعلام الحر، أخبار العراق وغيرها) تم ben رصدها في موقع التقنية و (إعلامي الوثائقية، جردية الدستور، قناة الرصافة الفضائية، أخبار الجزائر، خبر في دقيقة، guerdan dmc tv

\section{ب: الاراسة الميدانية}

سعت الباحثة في دراستها الميدانية أن نؤكد صحة المعلومات النظرية المتعلقة بآليات التحقق من الأخبار الكاذبة المنشورة في مو اقع الإعلام الاجتماعي من عدمها وكذلك سبل مواجتها، إذ وزعت الاستبانة إلكترونياً على 65 أستاذا مختصا في مجال 
الإعلام ممن استفادوا من دورات التربية الرقمية في داخل الكليات أو خارجها وكذلك أساتذة المادة المقررة في المناهج الدراسية من كليات و أقسام الإعلام المحلية وكانت النتائج كالآتي:

أولا: البيانات الأولية للمبحوثين تبين أن أغلب المبحوثين من أفراد العينة هم من الذكور بنسبة 58.5\% و 41.5\% من الإناث، كانت أعمار هم بين 45 فما فوق كنسبة أكبر 52.3\% وفيما كان من عمر هم 25-35 عام بنسبة 27.7\% أما من تتراوح أعمار هم بين 35-45 كانو ا بنسبة 20\%، يحمل 61.5\% منهم على شهادة الدكتور اهو 38.5\% على شهادة الماجستير، في حين أن 55.4\% منهم اختصاصهم صحافة وتوزعت النسب الأخرى على الاختصاصات الأخرى 24.6\% صحافة إذاعية و تلفزيونية و20\% علاقات عامة كما موضح في جدول (1)

جدول (1): البيانات الأولية للمبحوثين

\begin{tabular}{|c|c|c|c|c|c|c|c|c|c|c|}
\hline \multicolumn{3}{|c|}{ الاختصاص } & \multicolumn{3}{|c|}{ العمر } & \multicolumn{2}{|c|}{ التحصيل الدراسي } & \multicolumn{2}{|c|}{ الجنس } & \\
\hline علاقات & إذاعة & صحافة & 45 فما & -35 & $35-25$ & دكتور اه & ماجستير & انثى & ذكر & البيانا \\
\hline عامة & وتلفزيون & & فوق & 45 & & & & & & $ت$ \\
\hline 13 & 16 & 36 & 34 & 13 & 18 & 40 & 25 & 27 & 38 & 5 \\
\hline$\% 20$ & $\% 24.6$ & $\% 55.4$ & $\% 52.3$ & $\% 20$ & $\% 27.7$ & $\% 61.5$ & $\% 38.5$ & $\begin{array}{r}41.5 \\
\%\end{array}$ & $\begin{array}{r}58.5 \\
\%\end{array}$ & $\%$ \\
\hline
\end{tabular}

ثنانيا: استخدام مواقع الإعلام الاجتماعى والأخبار الكاذبة من خلال نتائج تحليل البيانات للاستبانة تبين أن جميع المبحوثين يتصفحون مواقع الإعلام الاجتماعي بنسبة 100\%، ففي جدول رقم (2) نبين أن أغلب أفراد العينة من الأساتذة يفضلون تصفح واستخدام تطبيق الفيسبوك بنسبة\%\%1.5\% ومن بعده تطبيق الواتس أب بنسبة 21.5\% ويأتي بعدها نطبيق تويتر وانستغرام بو اقع 6.15\% وأخيرا اليوتيوب بنسبة 4.61\% وهذا يدل على أن اغلب المبحوثين يستخدمون تطبيق الفيسبوك بشكل أكبر و أكثر من التطبيقات الإعلامية الاجتماعية الأخرى. جدول (2): يبين أكثر التطبيقات والمو اقع استخدام من قبل المبحوثين

\begin{tabular}{|c|c|c|}
\hline$\%$ & ك5 & التطبيق او الموقع \\
\hline$\% 61.5$ & 40 & الفيسبوك \\
\hline$\% 21.5$ & 14 & الو اتس اب \\
\hline$\% 6.15$ & 4 & تويتر \\
\hline$\% 6.15$ & 4 & انستغر ام \\
\hline$\% 4.61$ & 3 & يوتيوب \\
\hline$\% 100$ & 65 & المجموع \\
\hline
\end{tabular}


وفي سؤال وجه للمبحوثين حول أب التطبيقات أو المواقع تعتبر مصدراً للمعلومات و الأخبار فكانت إجاباتهم كما مبين في جدول رقم (3) بأن الفيسبوك هو أكثر المواقع تتو اجد فيه الأخبار ويكون مصدر الها بنسبة 43.07\% من أفراد العينة، وجاءت بعدها المو اقع الإعلامية سواء كانت الأخبارية أو التابعة لمؤسسات صحفية أو تلفزيونية مثل صفحة الشرقية نيوز و السومرية نيوز وخبر عاجل والحرة وصفحة سكابي نيوز و النبأ بنسبة 18.46\% بعدها تطبيق تويتير بواقع 13.84\% والواتس أب بنسبة \% 7.69 فيما اختار بعض المبحوثين جميع مواقع وتطبيقات الإعلام الاجتماعي كونها مصدر اً للاخبار بنسبة 6.15 أما تطبيق التلغر ام حصل على نسبة 4.61\% وكانت أقل نسبة لصفحات الإعلاميين وموقع اليوتيوب بنسبة 1.53\% . جدول (3): يبين المو اقع والتطبيقات التي تعتبر مصدراً للأخبار و المعلومات لدى المبحوثين

\begin{tabular}{|c|c|c|}
\hline النسبة المئوية & 5 & الموقع او التطبيث \\
\hline$\% 43.07$ & 28 & الفيسبوك \\
\hline$\% 18.46$ & 12 & المو اقع الإعلامية \\
\hline$\% 13.84$ & 9 & تويتر \\
\hline$\% 7.69$ & 5 & و اتس اب \\
\hline$\% 6.15$ & 4 & جميع مواقع الإعلام الاجتماعي \\
\hline$\% 4.61$ & 3 & التلغر ام \\
\hline$\% 3.07$ & 1 & يوتيوب \\
\hline$\% 3.07$ & 1 & صفحات الإعلاميين \\
\hline$\% 100$ & 65 & المجموع \\
\hline
\end{tabular}

ومن ناحية توصيف الأخبار الكاذبة فقد رأى المبحوثين أن الخبر الكاذب هو خبر مضُلل بنسبة 43.1\% بينما اعتبره الآخرون أنه خبر مفبرك وملفق بنسبة 38.5\% ومنهم من وصفه بالخبر المتحيز بنسبة 10.8\% في حين أن 4.61\% وصفه بأنه خبر يتضمن عنصر الإشاعة وقليل منهم وبنسبة 1.53\% اعنبره الخبر الكاذب هو خبر يحمل طابع السخرية أو عنصر المؤامرة كما موضح في جدول رقم (4) جدول (4): يبين تصنيف الأخبار الكاذبة من قبل المبحوثين

\begin{tabular}{|c|c|c|}
\hline$\%$ & ك5 & تصنيف الأخبار الكاذبة \\
\hline$\% 43.1$ & 28 & خبر مضئلل \\
\hline$\% 38.5$ & 25 & خبر مفبرك او ملفق \\
\hline$\% 10.8$ & 7 & خبر منحاز / متحيز \\
\hline$\% 4.61$ & 3 & يحمل طابع الثائعة \\
\hline$\% 1.53$ & 1 & يتضمن عنصر السخرية \\
\hline$\% 1.53$ & 1 & يحمل عنصر المؤامرة \\
\hline$\% 100$ & 65 & المجموع \\
\hline
\end{tabular}


في جدول رقم (5) وكما موضح يبين مميزات الأخبار الكاذبة وكيف يتم التعرف عليها وتنخيصها، فقد شخصوا الأخبار الكاذبة بأنها تتميز بالمزج بين الحقيقة والكذب بنسبة 30\% من أفراد العينة بينما ميزه آخرون بأنه خبر يتم نشره من مصادر غير معروفة ومجهولة بواقع 26.6\% في حين بَين أفراد منهم بأن الخبر الكاذب يتميز بعدم مطابقة أحداثه مع الواقع بنسبة 17.5\%، أما من وصفه بأنه خبر يضخّم الأحداث ويهولها بنسبة 11.6\% وآخرون يميزون الخبر الكاذب من خلال تفرد المو اقع بنشره دون المو اقع الأخرى بو اقع 7.5\% وميزه عدد من المبحوثين بأنه الخبر الذي يركز على جانب معين ويتغافل عن جانب آخر بمعنى أن يكون متحيز الجهة بنسبة 6.6\%. جدول (5): يبين مميزات الأخبار الكاذبة من قبل المبحوثين

\begin{tabular}{|c|c|c|}
\hline$\%$ & ك & مميزات الأخبار الكاذبة \\
\hline$\% 30$ & 36 & يمزج بين الحقيقة و الكذب \\
\hline$\% 26.6$ & 32 & مصدره مجهول وغير معروف \\
\hline$\% 17.5$ & 21 & عدم مطابقة الاحداث مع الو اقع \\
\hline$\% 11.6$ & 14 & يضخم الاحداث ويهولها \\
\hline$\% 7.5$ & 9 & تنفرد بعض المو اقع بنشره دون غير ها \\
\hline$\% 6.66$ & 8 & يركز على جانب معين ويتغافل عن أخرى/ متحيز \\
\hline$\% 100$ & 120 & المجموع* \\
\hline
\end{tabular}

في سؤال وجه إلى المبحوثين عن آلبات التحقق من الأخبار الكاذبة التي تنشر ها مواقع الإعلام الاجتماعي فقد تبين كما موضح في جدول رقم (6) بان المبحوثين يلجأون إلى البحث عن المصدر الرئيسي للخبر بنسبة 35.65\%؛ ومنهم يتحقق من الخبر عن طريق البحث عنه في مو اقع أخرى قد نشرته بنسبة 22.6\% و يلجأ آخرون من أفراد العينة إلى البحث عن الخبر في محركات البحث وخدماتها للكثف عن حقبقته بنسبة 15.65\% بينما يتحقق بعضهم من مصدر الخبر هل هو مصدر معروف أو مجهول بنسبة 10.43\% في حين يسعى آخرون للتحقق من الخبر عن طريق مضمونه باحتو ائه على معلومات خاطئة أو منحازة وربما قديمة وغير دقيقة بنسبة 6.08\% ويتأكد عدد من المبحوثين من مكان وزمان الأحداث التي يتضمنها الخبر بنسبة 5.21\% وأوضح اخرون بأنهم يتحققون من الخبر عن طريق تضمينه للحقائق والمعلومات أم يعبر عن وجهة نظر بنسبة 2.6\%وفضل بعض المبحوثين للتحقق من الخبر الكاذب عن طريق الاستفسار من الأهل والأصدقاء بنسبة 1.73\%. 
جدول (6): يبين آليات التحقق من الأخبار الكاذبة من قبل المبحوثين

\begin{tabular}{|c|c|c|}
\hline$\%$ & ك5 & آليات التحقق \\
\hline$\% 35.65$ & 41 & البحث عن المصدر الرئيسي للخبر \\
\hline$\% 22.6$ & 26 & التحقق من وجود مو اقع أخرى نشرت الخبر نفسه \\
\hline$\% 15.65$ & 18 & ابحث عن الخبر في محركات البحث وخدماتها \\
\hline$\% 10.43$ & 12 & ان يكون مصدره معروف او مجهول \\
\hline$\% 6.08$ & 7 & احتو ائه على معلومات خاطئة او منحازة ام غير دقيقة \\
\hline$\% 5.21$ & 6 & التأكد من تاريخ وزمان الحدث \\
\hline$\% 2.6$ & 3 & يعطي معلو مات ام يعبر عن وجهة نظر \\
\hline$\% 1.73$ & 2 & الاستفسار من الاهل و الأصدقاء \\
\hline$\% 100$ & 115 & المجموع* \\
\hline
\end{tabular}

*المجموع يختلف نظر أ لتعدد الاختيار ات من قبل المبحوثين

فيما يتعلق بكيفية مواجهة الأخبار الكاذبة فكما موضح في جدول رقم (7) بأن أغلب افراد العينة يهملون الخبر بعدم وضع الإعجاب أو المشاركة أو نرك أي تعليق بنسبة 44.6\% في حين يواجه آخرون الأخبار الكاذبة بالمواجهة والمكاثفة بالتعليق عليها بأنها أخبار كاذبة، ويجب عدم الوثوق بها وتصديقها بنسبة 27.7\% ويحاول البعض منهم تحذير الآخرين من خلال إعادة نشره وتبليغهم بعدم مصداقيته بنسبة 13.8\% أما البعض الآخر من أفراد العينة يفضلون تبليغ إدارة الموقع عن ناشر الخبر بنسبة 7.7\% وقد يلجأ أحدهم إلى الوصول لمصدر الخبر والتو اصل معه لمعرفة الحقيقة كانو ا بنسبة 4.61\% وفضل عدد قليل منهم أن يترك الأمر و لا يفعل شيئًا بنسبة 1.53\%.

جدول (7): يبين كيفية مواجهة الأخبار الكاذبة من قبل المبحوثين

\begin{tabular}{|c|c|c|}
\hline$\%$ & ك5 & مواجهة الخبر الكاذب عن طريق \\
\hline$\% 44.6$ & 29 & 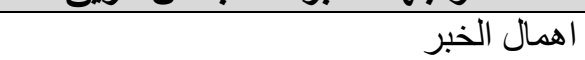 \\
\hline$\% 27.7$ & 18 & التعليق بعدم مصداقيته و انه خبر كاذب \\
\hline$\% 13.8$ & 9 & محاولة تحذير الاخرين من خلال إعادة النشر \\
\hline$\% 7.7$ & 5 & تبليغ إدارة الموقع عن ناشر الخبر \\
\hline$\% 4.61$ & 3 & الوصول الى مصدر الخبر و التو اصل معه \\
\hline$\% 1.53$ & 1 & لا افعل شيئًا \\
\hline$\% 100$ & 65 & 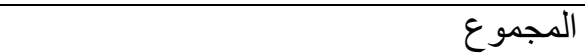 \\
\hline
\end{tabular}

في جدول رقم (8) يحصل الفيسبوك على المرنبة الأولى بنشر الأخبار الكاذبة حسب رأي المبحوثين بنسبة 48.06\% بينما أكد آخرون بأن المواقع والصفحات الثخصية في مواقع الإعلام الاجتماعي هي التي تنشر الأخبار الكاذبة بكثافة أكبر وبنسبة 10.85\% وبعدها يأتي تطبيق الو اتس أب والانستغر ام بواقع 9.3\% ومن ثم تطبيق التلغرام بنسبة 8.52\% وقد ينشر تويتر و المو اقع الإعلامية اخباراً كاذبة بنسبة 5.42\% وأخيرا نطبيق التيك توك بنسبة 3.1\%، وتأتي هذه النسبة بالتوافق مع استخدامات المبحوثين لتلك المو اقع و التطبيقات. 
جدول (8): يبين المواقع والتطبيقات التي تنشر الأخبار الكاذبة حسب راي المبحوثين

\begin{tabular}{|c|c|c|}
\hline$\%$ & ك5 & الموقع او التطبيق \\
\hline$\% 48.06$ & 62 & الفيسبوك \\
\hline$\% 10.85$ & 14 & المو اقع والصفحات الثخصية \\
\hline$\% 9.3$ & 12 & انستغرام \\
\hline$\% 9.3$ & 12 & الو اتس اب \\
\hline$\% 8.52$ & 11 & التلغر ام \\
\hline$\% 5.42$ & 7 & تويتر \\
\hline$\% 5.42$ & 7 & المو اقع الإعلامية \\
\hline$\% 3.1$ & 4 & تيلك توك \\
\hline$\% 100$ & 129 & المجموع \\
\hline
\end{tabular}

الاستنتاجات:

1ـ هناك اختلاف بين موقعي التحليل التقنية من أجل السلام، ومنصة فتبينوا من حيث كثف الأخبار الكاذبة وتوثيق الحقيقة حسب طبيعة عمل كل منهما واهتماماته سواء على الصعيد المحلي أو العربي والعالمي. إذ اهتمت صفحة التقنية بكثف الأخبار المتعلقة بالمضامين الأمنية والسياسية لما لها أهمية على المستوى المحلي وتأثير ها على الر أي العام، بينما سعت منصة فتبينو ا إلى كثف الأخبار الكاذبة المتعلقة بالمضامين المنوعة والصحة كون الموقع يخاطب المجتمع العربي وليس المحلي فقط.

2-كانت المضامين السياسية والأمنية مسيطرة على محتوى الأخبار الكاذبة التي يتداولها المستخدمون نظرا لأهمية تلك الموضو عات وتأثير ها في تشكيل اتجاهات الر أي العام بما يخدم أهداف مروجيها، خصوصا أن بعض البلدان العربية تعاني من أزمات سياسية وأمنية داخل حكو ماتها ومجتمعاتها.

3-أكثر الأخبار الكاذبة التي كثف عنها الموقعين هي أخبار مُضللة تحمل أنصاف الحقائق وأخبار ا مفبركة وملفقة تحاكي و اقع مزيف، وقد تتضمن تللك الأخبار مضامين تتعلق بإثارة وبث الثائعات بين الجمهور وأخرى قلبلة تحوي عنصر التحبز لجهة معينة أو نظرية المؤامرة، إذ تأخذ في مضامينها أفعال مؤذية أو غير قانونية تجريها حكومة أو جهات أخرى قوية.

4-أغلب الأخبار الكاذبة تستخدم وسيطين مثل النص و الصورة فغالباً ما يكون النص لا يتعلق بالصورة أو الصورة مفبركة أو يكون النص ملققا وأحيانا أخرى هناك أخبار تستخدم النص و الفيديو وربما تستخدم نص فقط يكون هذا النص زائف أو ملقق، وقد يكون الخبر الكاذب على شكل صورة وهذه الصورة منلاعب بها وينطبق ذلك على مقاطع الفيديو.

5-المو اقع التي تتشر الأخبار الكاذبة وتساهم في انتشار ها أغلبها صفحات عامة (مجهولة) في مو اقع الإعلام الاجتماعي خاصة في الفيسبوك ربما يدير ها شخص أو مجموعات، في حين هناك صفحات شخصية ساهمت أيضا في نشر الأخبار الكاذبة 
وتوسيع دائرة انتشارها من قبل الأفراد، كما ساهت صفحات المواقع الإعلامية في نشر الأخبار الكاذبة وانتشار ها بين الجمهور.

6-يعتبر الفيسبوك مصدراً للأخبار لكنه في نفس الوقت هو من أكثر مواقع الإعلام الاجتماعي نشراً للأخبار الكاذبة وتداولها خصوصاً الصفحات الشخصية للأفر اد.

7-أجمع المستخدمون لمواقع الإعلام الاجتماعي بأن الخبر الكاذب يتصف، بأنه خبر مُضلل وخبر مُفبرك يتضمن التزييف و التلفيق وقد يتم التلاعب في مضمونه حسب أهداف ناشرهِ. ومن مميز اته أنه يَزج بين الحقيقة و الكذب و مصدره مجهول وغير معروف و عدم مطابقة أحداثه مع الواقع. 8-يتم التحقق من الأخبار الكاذبة من قبل المستخدمين لمو اقع الإعلام الاجتماعي، عن طريق البحث عن المصدر الرئيسي للخبر ومن وجود مو اقع أو صفحات أخرى نشرت الخبر نفسه إضافة إلى البحث عن الخبر في محركات البحث وخدماتها للكثف عن الحقيقة.

9-يتم مواجهة الأخبار الكاذبة من قبل المستخدمين لمواقع الإعلام الاجتماعي عن طريق إهمال الخبر (عدم ترك أي تعليق أو اعجاب أو مشاركة) ومنهم من يكثفه للآخرين ويحاول تحذير هم من الوثوق به، والقلة من بستخدم ميزة تبليغ إدارة الموقع عن ناشر الخبر الكاذب في صفحته أو الوصول الى مصدر الخبر والتو اصل معه. 
- زرو اتي رشيد، تدريبات على منهجية البحث العلمي في العلوم الاجتماعية، ديوان المطبوعات الجامعية، الجزائر، ط3، بلا

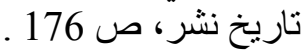

ـ عبد الله عبد الرحمن الكندري ومحمد احمد عبد الدايم، المنهجية العلمية في البحوث التربوية والاجتماعية، مؤسسة الابتكار

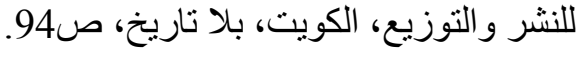
- وجيه محجوب، البحث العلمي ومناهجه، دار الحكمة للطباعة والنشر، بغداد، 2002م، ص163. * أسماء الأساتذة المحكمين لاستمارة التحليل والاستبانة: 1- أ.د سعد سلمان المشهداني/ قسم الإعلام كلية الآداب جامعة تكريت2- أ.د محمد جياد/قسم العلاقات العامة كلية الإعلام

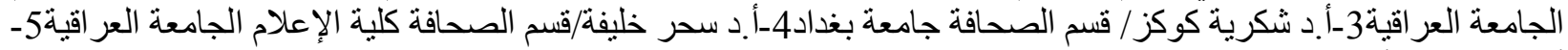

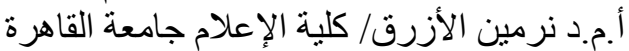

ـ مها السيد بهنسي، آليات مستخدمي الثبكات الاجتماعية في التحقق من الأخبار الزائفة، القاهرة، المجلة المصرية لبحوث الإعلام، المجلد 2019، العدد 68، الصيف 2019، الصي الصفحة 614-565.

ـ عبد الرزاق محمد الدليمي، إثكاليات الأخبار المفبركة وتأثير ها في تشكيل الراي العام، دراسات اعلامية، مركز الجزيرة

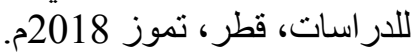
https://studies.aljazeera.net/sites/default/files/articles/mediastudies/documents/893bced5cf72499 ca42563df0f9c2879_100.pdf

ـ ايناس بوسعيدس، آليات التحقق من الأخبار المتدققة عبر الإعلام الاجتماعي، دراسة حالة، قطر، معهد الجزيرة للاعلام 2018،

https://institute.aljazeera.net/sites/default/files/2018/\%D8\%A2\%D9\%84\%D9\%8A\%D8\%A7\% D8\%AA\%20\%D8\%A7\%D9\%84\%D8\%AA\%D8\%AD\%D9\%82\%D9\%82\%20\%D9\%85\%D9\% 86\%20\%D8\%A7\%D9\%84\%D8\%A7\%D8\%AE\%D8\%A8\%D8\%A7\%D8\%B1_0.pdf ـمحد الراجي، صناعة الأخبار الكاذبة ولولب الحصار المعلوماتي للراي العام، قطر، مركز الجزيرة للار اسات،2018م. https://studies.aljazeera.net/ar/mediastudies/2018/05/180527110035087.html ـ مجموعة باحثين، البحث عن الحقيقة في كومة الأخبار الكاذبة جمع الأخبار و التحقق منها على شبكات التو اصل الاجتماعي

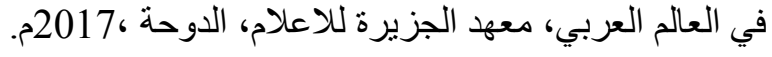

https://institute.aljazeera.net/sites/default/files/2018/\%D8\%A7\%D9\%84\%D8\%A8\%D8\%AD\%D 8\%AB\%20\%D8\%B9\%D9\%86\%20\%D8\%A7\%D9\%84\%D8\%AD\%D9\%82\%D9\%8A\%D9\%82 \%D8\%A9\%20\%D9\%81\%D9\%8A\%20\%D9\%83\%D9\%88\%D9\%85\%D8\%A9\%20\%D8\%A7\% D9\%84\%D8\%A3\%D8\%AE\%D8\%A8\%D8\%A7\%D8\%B1\%20\%D8\%A7\%D9\%84\%D9\%83\%D 8\%A7\%D8\%B0\%D8\%A8\%D8\%A9.pdf

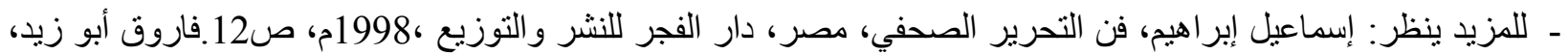

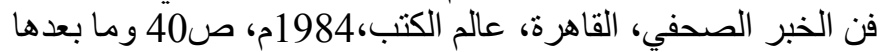
ـ علي منعم القضاة، كتابة متقدمة للأخبار و التقارير، ص28. الخبر الصحفي عنصر أساسي من عناصر العملية الإعلامية، 2004، ص344 وما بعدها ـ عبد اللطيف حمزة، المدخل في فن التحرير الصحفي، دار الفكر العربي، القاهرة، ص55و ص57.

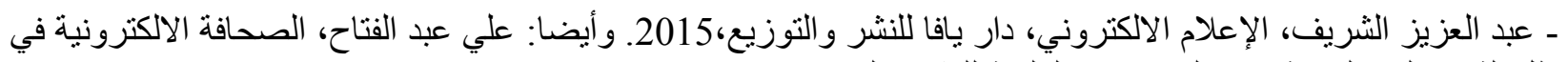

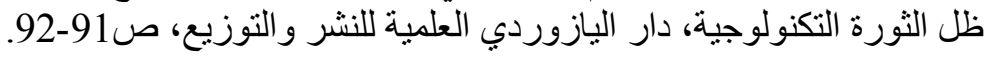
ـ محمود ادهم، فن الخبر مصادره وعناصرهو ومجالاته والحصول عليه، ط2، القاهرة، هليو بوليس،1987، ص570 
ـ معجم المعاني، النسخة الالكترونية متوفر على الر ابط: https:/www.almaany.com/ar/dict/ar تعريف ومعنى إثاعة في قاموس المعجم الوسيط، اللغة العربية المعاصرة، الرائد، لسان العرب، القاموس المحيط. قاموس عربي عربي

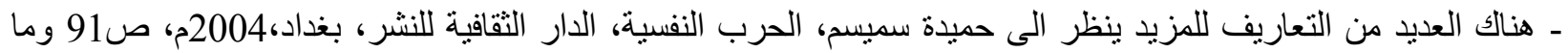

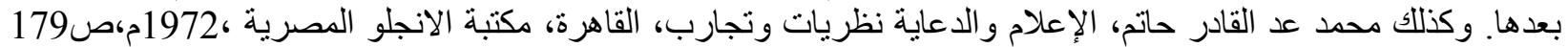
وما بعدها

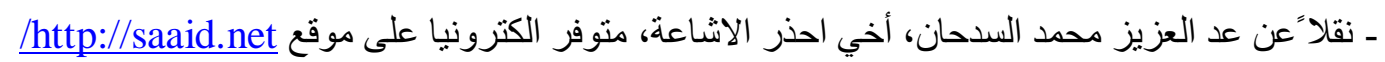
ـ نقلا عن عوض عز الرجال عفيفي، الاشاعة التعريف والخطر والتاريخ والسمات، حث منشور الكترونيا على الرابط

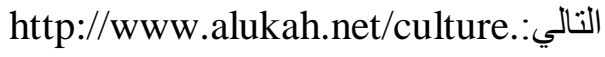
ـ مجمو عة باحثين، محاربة الثائعات،2012الرؤيا للإعلام، قطر، ص13 منوفر بنسخة بي دي اف. - حميدة سميسم، الحرب النفسية، ص92. - جمال الرزن، الأخبار الكاذبة، مكتبة جامعة قطر، ندوة،2018م ،ص11 منوفر بي دي اف على شبكة الانترنت.

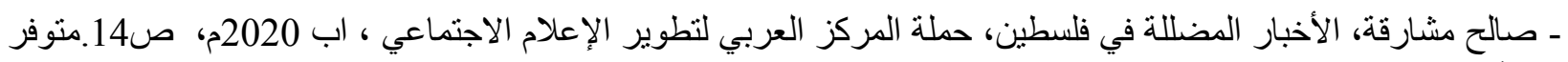
نسخة بي دي اف مثار

https://www.bbc.com/arabic/science-and-tech 10اذار 2018م، ملخص لدراسة حول الأخبار الزائفة نشرت في موقع بي بي سي عربي ، نم زيارة الموقع في 2020/9/25م

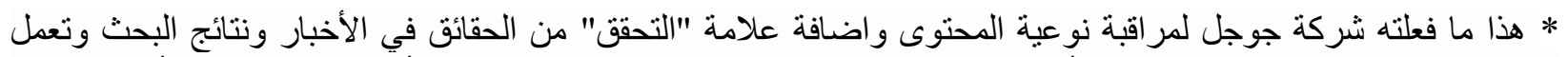

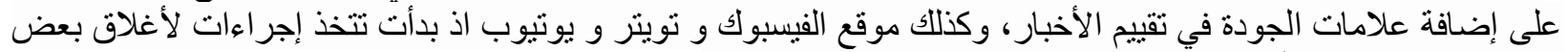

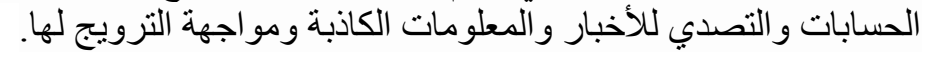
- صالح مشارقة، مرجع سبق ذكره، ص111. ـ نقلا عن: مها السيد بهنسي، آليات مستخدمي شبكات التواصل، ص567 مكرد

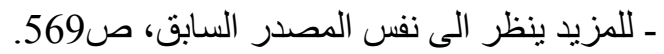
*قام موقع الفيسبوك بتحديد تلك الارشادات ونشر ها في اعلان بصحيفة الجارديان البريطانية: نقلا عن د. محمود احمد عبد الله،

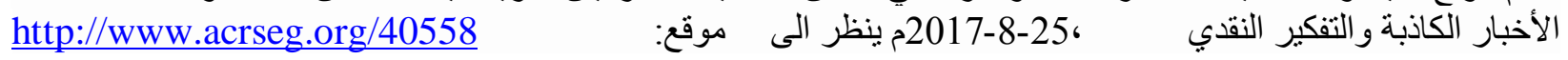
ـ للمزيد حول اساسيات التحقق من المحتوى على الانترنت ينظر : لينا عجيلات، دليل التربية الإعلامية الرقمية، معهد الإعلام

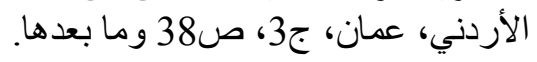

